\title{
A lógica da construção de confiança: Relações Brasil-Suriname entre 1975 e 1985
}

Towards confidence building:

Brazil-Suriname relations between 1975 and 1985

JOÃO NACKLE URT*

Rev. Bras. Polít. Int. 53 (2): 70-87 [2010]

\section{Introdução}

O presente artigo trata das relaçóes bilaterais Brasil-Suriname, tendo como marco temporal inicial a independência do Suriname (1975) e como marco final, o término do governo Figueiredo no Brasil (1985). O destaque vai para as relaçôes havidas a partir de 1982, ano em que um novo golpe de Estado indicou que o Suriname poderia se tornar uma ditadura de esquerda, aliada de Cuba e da Líbia. Nesse momento, enquanto Países Baixos e Estados Unidos optaram por tentar sufocar a rebelião surinamesa por meio do corte da ajuda financeira que davam ao país, o governo brasileiro enviou uma missão diplomática para aprofundar o diálogo e oferecer uma opção ao Suriname. Enquanto os Estados Unidos intervinham militarmente em Granada, a pouco mais de mil quilômetros de distância da costa surinamesa, o Brasil escolheu o caminho da cooperação para evitar a "cubanização" de seu vizinho. Conclui-se que ao longo desse período, o Brasil buscou assegurar relações confiáveis com seu mais novo vizinho sem despertar protestos de hegemonia ou satelitização, orientando-se pelo objetivo da construção de confiança regional.

O primeiro tópico apresenta o Suriname, sua situação geográfica e parte de sua história, desde o processo de independência, passando pela "rebelião dos sargentos" em 1980, até a radicalização sob o governo do comandante Desiré Bouterse, a partir de 1982. Apresentam-se também alguns aspectos das relações internacionais do Suriname e de sua política externa. Nos dois tópicos seguintes, descreve-se a situação internacional do Brasil na segunda metade da década de 1970, as linhas gerais da política externa dos governos Geisel e Figueiredo, e apresenta-se um breve histórico das relações do Brasil com o Suriname, com as principais visitas oficiais e, sobretudo, a "missão Venturini” de 1983 e seus resultados.

\footnotetext{
* Mestre em Relações Internacionais pela Universidade de Brasília - UnB e professor da Universidade Federal
} de Roraima - UFRR (joaourt@gmail.com). 


\section{Suriname: breve história política e inserção internacional (1975-1985)}

O sistema político que existiu no Suriname entre 1975 e 1980 combinava diversas características. Foi constituído como uma democracia parlamentar de inspiração ocidental, mas combinava características do apanjaht e da democracia consorcional. O apanjaht era o sistema de partidos com identificação étnica e correspondente disposição popular de votar por sua própria raça. Os principais partidos políticos do Suriname eram ligados aos crioulos, hindustanis e javaneses, grupos étnicos que juntos detinham quase $80 \%$ dos votos. A democracia consorcional, por sua vez, importada dos Países Baixos, consistia numa forma de governo em que as divisões étnicas eram apaziguadas por meio de sistemas de proporcionalidade e compartilhamento de poder (MACDONALD, 1988:106).

O governo de Henck Arron, primeiro-ministro eleito em 1973 e autor da proclamação de independência de 1975, transcorreu sem grandes percalços, a despeito dos conflitos étnicos e da maioria apertada no Parlamento. Em janeiro de 1980, a crise econômica e social refletiu-se numa greve de soldados do exército. A resistência do governo em ceder às exigências dos suboficiais e dos soldados prolongou as tensões. Em 25 de fevereiro de 1980, três sargentos do Exército lideraram entre 150 e 300 soldados numa rebelião que derrubou o poder estabelecido (JORNAL DO BRASIL, 1980c).

Após o sucesso do levante, os líderes da rebelião, os sargentos Badresein Sital e Laurens Neede - auto-proclamados Conselho Militar Nacional, juntamente com o sargento Desi Bouterse e outros - publicaram um comunicado em nome dos revoltosos, em que garantiam o respeito aos princípios democráticos e ao interesse geral da população do Suriname, e pediam ao povo a obediência às ordens do Conselho (JORNAL DO BRASIL, 1980a; O GLOBO, 1980b). No dia 28 de fevereiro, o sargento Neede confirmou a suspensão por tempo indeterminado das eleiçôes marcadas para o dia 27 de março de 1980.

A "rebelião dos sargentos", como ficou conhecido o episódio, foi um golpe militar atípico. Não tinha caráter revolucionário, nem reacionário. Não partiu de preocupaçôes relacionadas à Guerra Fria. Não seguiu a lógica das doutrinas de segurança inspiradas nos Estados Unidos, nem de alinhamentos à União Soviética. Foi um levante militar provocado por questões exclusivamente internas, quase que limitadas ao espectro das relaçôes da classe militar com o governo. Mas o caráter não-ideológico do levante não era evidente para a comunidade internacional. Os Estados Unidos estavam preocupados nessa época com a disseminação de revoluçōes marxistas na América Central e no Caribe. A Revolução Sandinista logrou tomar o poder em 1979 na Nicarágua, reanimando o movimento revolucionário também em El Salvador (ATKINS, 1999:309). Jamaica e Granada estavam se aproximando de Cuba em 1980. No norte da América do Sul, ao lado do Suriname, a Guiana servira de "ponto de reabastecimento de aviōes cubanos a caminho de Angola". Os norte-americanos cogitaram estabelecer uma base da 
OTAN em alguma das colônias insulares holandesas (CARLOS, 1980). Com a reversão da ordem constitucional, o Suriname poderia se tornar um foco de instabilidade na América do Sul.

O presidente Johan Ferrier, que no regime parlamentarista surinamês representava mais uma autoridade moral que política, inicialmente foi mantido no posto, compondo o governo com membros de partidos minoritários de esquerda e partidos da oposição. Os três antigos partidos do apanjaht, desacreditados entre os novos governantes militares, foram banidos. O poder passou a ser exercido de fato pelo Conselho Nacional Militar.

Em agosto de 1980, um segundo golpe - dirigido pelo agora tenentecoronel, Comandante do Exército e chefe do Conselho Nacional Militar, Desi Bouterse - depôs o presidente Ferrier e o substituiu por Henk Chin-A-Sen, que ocupava até então o cargo de primeiro-ministro (O GLOBO, 1980c; JORNAL DO BRASIL, 1982a).

Afirmou-se que o principal objetivo do golpe de agosto era "alijar do Governo pessoas favoráveis a Cuba" (JORNAL DO BRASIL, 1982a). Mas essa afirmação mal-esconde a complexidade da situação. Primeiro, porque a presença da esquerda no governo era necessária para que se pudesse contar com parceiros civis e estabelecer legitimidade popular. Segundo porque o principal objetivo do golpe era mesmo fortalecer e consolidar a presença dos militares no governo (MACDONALD, 1988:108). E terceiro porque o próprio Bouterse se mostraria simpático ao socialismo cubano nos anos seguintes, de maneira que não se sabe ao certo se o que houve foi uma mudança na orientação ideológica de Bouterse, simples oportunismo pragmático ou se o comunicado foi apenas uma mentira utilizada para justificar a deposição de Ferrier.

Assim, o período entre 1980 e 1982 foi de consolidação dos militares no poder e eliminação de rivais (MACDONALD, 1988:108). Essa fase intermediária incluiu o desmantelamento de um golpe organizado pelo vice-presidente deposto André Haakmat em 1981, e encerrou-se com dois novos golpes de estado em 1982, o primeiro, bem sucedido e o segundo, não.

No dia 4 de fevereiro de 1982, antes do segundo aniversário da rebelião dos sargentos, os militares surinameses, liderados mais uma vez pelo Comandante do Exército Desi Bouterse, depuseram o presidente Chin-A-Sen. A presidência da República passou a ser exercida interinamente por Bouterse. Embora Chin-A-Sen ocupasse apenas um cargo decorativo - o poder estava nas mãos de Bouterse e seus aliados militares desde 1980 (GUERREIRO, 1985; FOLHA DE S. PAULO, 1982a; MACDONALD, 1988:108) -, o clima político no país, poucos dias antes do golpe, parecia estável. O presidente Chin-A-Sen contava com apoio popular e sindical, e os diplomatas brasileiros servindo em Paramaribo não perceberam qualquer anormalidade. Poucos dias antes do golpe - no dia 25 de janeiro de 1982 -, o chanceler brasileiro, Saraiva Guerreiro, havia visitado o Suriname e fora recebido conjuntamente pelo presidente Chin-A-Sen e pelo coronel Bouterse 
sem que houvesse nenhuma animosidade aparente (JORNAL DO BRASIL, 1982a). Os motivos do golpe de 4 de fevereiro foram os desentendimentos entre o Conselho Nacional Militar e o presidente quanto à orientação pró-socialista e do estreitamento dos laços com Cuba, defendidos por Bouterse, bem como quanto ao retorno das eleiçóes diretas, defendido por Chin-A-Sen (DEW, 1983:4; O GLOBO, 1982a).

O segundo golpe partiu de um grupo de dissidentes da rebelião dos sargentos, insatisfeitos com os rumos que o país vinha tomando, sobretudo com a orientação socialista e neutralista imposta por Bouterse. No dia 11 de março de 1982, oficiais direitistas chefiados pelos tenentes Surendre Rambocus e Henri Gorre e pelo sargento-major Wilfred Hawker anunciaram ter deposto o governo esquerdista do Suriname. Mas o presidente conseguiu escapar e reuniu suas forças nos arredores da capital, preparando uma contra-ofensiva eficaz. No dia 15 de março, Bouterse já tinha retomado o poder após haver capturado e fuzilado o sargento-major Hawker (DEW, 1983:4; CORREIO BRAZILIENSE, 1982a; O GLOBO, 1982b; JORNAL DA TARDE, 1982; FOLHA DE S. PAULO, 1982b).

Em $1^{\circ}$ de abril de 1982, foi empossado um novo governo civil, liderado pelo primeiro-ministro Henry Neyhorst. Após uma série de greves e protestos contra a orientação considerada excessivamente esquerdista do governo, o coronel Desi Bouterse voltou a assumir o controle absoluto do Suriname em 8 de dezembro de 1982 (DEW, 1983:4-5; FOLHA DE S. PAULO, 1982c). Na semana seguinte, quinze líderes da oposição foram fuzilados pelo governo de Bouterse. Trinta e seis outros opositores foram assassinados sob alegação de estarem tentando escapar da prisão (DEW, 1983:6). Após esses fatos, que ficaram conhecidos como o "massacre de dezembro", o regime impôs um rigoroso toque de recolher, censurou a imprensa e interrompeu as comunicações com o exterior.

A repressão no Suriname, segundo testemunhos, contava com a participação de agentes cubanos e nicaragüenses. Na Europa e nos Estados Unidos, surgiram preocupações de que o Suriname pudesse se transformar em "uma 'cabeça de ponte' cubana para ameaçar as Antilhas Holandesas, no Caribe, a Guiana, a Venezuela e o próprio Brasil" (O GLOBO, 1982c). As mortes de dezembro de 1982 marcam o fim da fase de consolidação de Desi Bouterse no poder e o início de um governo autoritário que apenas se encerraria em 1986.

O massacre de dezembro provocou reações intensas no meio internacional. Os Países Baixos suspenderam prontamente a ajuda financeira prestada desde 1975. Os Estados Unidos também suspenderam a ajuda econômica de US\$1,5 milhão que davam ao país (MACDONALD, 1988:109; O GLOBO, 1982c; JORNAL DO BRASIL, 1982b).

Entre 1980 e 1982, os observadores internacionais acreditavam que o país estava passando por uma guinada rumo à esquerda. Em diversas circunstâncias, Bouterse afirmou que transformaria o Suriname em um país socialista e revolucionário e conduziu as relações internacionais do Suriname para um novo 
formato. Desapareceu a quase-exclusividade de relações com a antiga metrópole, os Países Baixos, e com a superpotência capitalista, os Estados Unidos, em favor de uma diversificação de contatos, sobretudo com representantes da esquerda latinoamericana. Foram estabelecidas relaçôes com os sandinistas na Nicarágua, com Cuba e com o movimento New Jewel em Granada. A Líbia também intensificou sua atuação no Suriname (MACDONALD, 1988:118).

Os holandeses, cuja reação em 1980 fora apenas de desapontamento, foram duros após o massacre de 1982. Suspenderam a ajuda financeira e se mantiveram comprometidos com a democratização do Suriname, em oposição a Bouterse. Com efeito, a perspectiva de liberação dos US $\$ 750$ milhôes restantes da ajuda prometida em 1975 era uma forte motivação para os opositores de Bouterse no Suriname. Os Estados Unidos se mantiveram afastados. Embora tenham cogitado promover um golpe para depor Bouterse, acabaram dando preferência às atuaçóes holandesa, brasileira e francesa que, do ponto de vista americano, serviam bem aos seus interesses (MACDONALD, 1988:117-118).

Os líbios chegaram a manter uma missão de aproximadamente cem instrutores militares. Acreditava-se que a Líbia poderia mandar tropas, caso o governo de Bouterse fosse desafiado por potências estrangeiras. O Suriname era considerado estratégico para os líbios em razão de sua vizinhança com a Guiana Francesa e sua proximidade com o Caribe, onde havia grandes interesses norteamericanos e franceses. A presença líbia foi intensificada entre 1983 e 1986. Vale lembrar que a Líbia era considerada um inimigo perigoso do Ocidente capitalista, e colaborou com atividades terroristas contra pessoal norte-americano na Alemanha Ocidental, provocando a retaliação dos Estados Unidos com um ataque a Trípoli em 1986 (MACDONALD, 1988:114). Nicaragüenses e cubanos também intensificaram suas relaçôes com o Suriname em 1982. Os sandinistas da Nicarágua enviaram em torno de trinta a cinqüenta especialistas em logística e comunicações para organizar os "comitês populares" organizados pelo regime de Bouterse e criar uma milícia popular. Cuba foi um centro de treinamento de membros do partido de esquerda surinamês, o Partido Revolucionário do Povo (RVP). Cogita-se que tenha havido uma presença de quinhentos cubanos no Suriname, e que eles tenham sido os responsáveis pelas execuçōes de dezembro de 1982 (O GLOBO, 1982c). Observadores internacionais afirmaram que o Suriname estava caminhando para um regime comunista ao estilo cubano (O ESTADO DE SÃO PAULO, 1982). Segundo observadores diplomáticos brasileiros, não houve chegada de professores, técnicos agrícolas, enfermeiros ou outros quadros cubanos: "claramente Cuba não optou, por enquanto ao menos, por dar ao Suriname uma assistência maciça, a exemplo do que fez em outros países”. Não obstante, a conclusão "tentativa" extraída destas "informações" (referidas assim mesmo com aspas no original) foi a seguinte: "Cuba está desenvolvendo aqui uma estratégia original e tentativa que visa a induzir, cirurgicamente, o Suriname a se transformar em República Popular" (CIEX, 1983b). 
Desde o começo, mas principalmente após 1982, Desi Bouterse não mostrou ter um projeto estratégico claro para a inserção internacional do Suriname. Macdonald descreve a orientação internacional surinamesa sob Bouterse como errática, entre a esquerda e a direita (1988:109).

Para tentar compreender esse "movimento errático" da política externa surinamesa, vale recorrer às forças profundas e aos homens de Estado, à moda da Escola Francesa de história das relações internacionais. Entre as forças profundas deve-se destacar: (1) as constantes tensões interétnicas, herança do projeto colonizador neerlandês; (2) a dependência econômica da produção e exportação de bauxita; e (3) a adoção do autoritarismo como regime de governo.

Sobre o primeiro ponto: a força das identidades étnicas - o sentimento de pertencer a um determinado grupo racial - sobrepujando a identidade nacional no Suriname dessa época, foi um poderoso fator de instabilidade.

Quanto à dependência da bauxita, a renda oriunda do extrativismo mineral provoca efeitos sociais e econômicos danosos, conhecidos como "doença holandesa". As enormes margens de lucro do extrativismo superam facilmente outras fontes de renda. O câmbio é apreciado, favorecendo as importaçōes de bens de consumo e prejudicando outros setores de exportação. Os setores agrícola e industrial entram em declínio, tornando a economia cada vez mais dependente do setor extrativista mineral e emulando comportamentos de rent-seeking. Além disso, como o setor extrativista é intensivo em utilização de capital, ele provê poucos empregos e poucas conexões com o restante da economia (COPINSCHI, 2007:126). O Suriname sofre, portanto, com uma "maldição da bauxita", semelhante à "maldição do petróleo". Os resultados sociais, no período estudado, foram o inchaço do setor governamental, com mais de um quarto da população economicamente ativa empregada no funcionalismo público; a adoção de práticas sociais pervertidas, como o regime do "padroado", que consistia na troca de um cargo de funcionário pelos votos de uma família - uma espécie de rent-seeking; e, finalmente, a exacerbação das disputas por renda e sua tradução em movimentos sociais violentos, como a rebelião dos sargentos, cujo objetivo mal-disfarçado era, em última análise, a obtenção pela força das vantagens escassas oriundas da renda do extrativismo da bauxita.

O regime autoritário também é um aspecto essencial dentro do sistema de causalidades que ajuda a explicar as relações internacionais do Suriname. Segundo Gaddis, esse regime de governo atrapalha a formulação de uma política externa condizente com a realidade, porque os atores governamentais se sentem pouco à vontade para contrariar o chefe de Estado, mesmo que se apercebam de seus erros, produzindo assim um processo irracional de tomada de decisões (GADDIS, 1997:506). No caso de Bouterse, o assassinato não apenas de opositores mas também de ex-colaboradores de seu regime criou um clima pouco favorável à expressão de opiniōes contrárias e ajudou a produzir um governo incoerente. 
Quanto à psicologia de Desi Bouterse, existem mais dúvidas que certezas. É possível que se trate de uma personalidade psicótica - o que não é raro entre ditadores - a julgar por fatos como sua ameaça de inundar a capital Paramaribo explodindo a represa a jusante, caso ele fosse derrotado pelas forças rebeldes (MACDONALD, 1988:109), além dos testemunhos de que o ditador executou pessoalmente alguns de seus inimigos (DEW, 1983:4; O ESTADO DE SÃO PAULO, 1983a). Mas é também possível que sua aparente irracionalidade fosse parte de um projeto pragmático destinado a conseguir no exterior os insumos financeiros para sua manutenção no poder, em substituição às verbas que acabara de perder dos Países Baixos e dos Estados Unidos. Assim, à moda da eqüidistância pragmática praticada pelo Brasil durante a Segunda Guerra Mundial, é possível que Bouterse tenha se aproveitado da Guerra Fria e das animosidades entre Brasil e Cuba, para tentar obter vantagens destinadas ao sucesso de seu projeto pessoal de poder.

\section{Política externa brasileira para o Suriname entre 1975 e 1979}

O cenário internacional marcado pela crise do petróleo vinha impondo transformaçōes à política externa brasileira. A política externa iniciada pelo general Ernesto Geisel em 1974 estava fundada em duas diretrizes: assegurar o fornecimento de petróleo e garantir mercados de exportação para os produtos brasileiros. Um de seus reflexos na prática foi o abandono do apoio ao colonialismo português, com o imediato reconhecimento da independência de Angola em 1975, a despeito da oposição da "linha-dura" do Exército (PINHEIRO, 1987). Entre esse grupo ainda era forte a doutrina das "fronteiras ideológicas", segundo o qual o conceito de soberania "não mais se fundaria em limites e fronteiras geográficas dos Estados e sim no caráter político e ideológico dos regimes" (MONIZ BANDEIRA, 2003:386).

Uma grande conquista do presidente Geisel em matéria de política externa foi tê-la libertado da "camisa de força ideológica que dificultara [...] a diversificação das relações do Brasil” (PINHEIRO, 2004:45), permitindo ao País comportar-se da maneira que fosse mais conveniente do ponto de vista do projeto nacional de desenvolvimento.

Assim, livre da doutrina das fronteiras ideológicas, o Brasil pôde começar a libertar-se da pecha de imperialista, subimperialista, ou aliado-chave dos Estados Unidos no subcontinente. A atuação continental do governo brasileiro durante os governos de Castelo Branco, Costa e Silva e Médici agravara as prevençôes em relação ao Brasil entre os vizinhos latino-americanos (URT, 2009:27-32). Pode-se mencionar aqui o apoio do governo brasileiro aos golpistas do Chile e da Bolívia em 1973. Nos governos de Geisel e Figueiredo, ao contrário, “o Brasil procurava desfazer a imagem de uma pretensa hegemonia perseguida no continente" (MIYAMOTO, 1989:147). Estava aberto o caminho para uma relação mais cooperativa com a América do Sul. 
Especificamente a região das Guianas passou a receber maior atenção do governo brasileiro, na década de 1970, em grande parte devido às doutrinas de geopolítica formuladas na Escola Superior de Guerra (ESG), que destacavam a necessidade de proteger as fronteiras e ocupar a Amazônia (KELLY, 1984:459).

A política externa brasileira de apoio à descolonização permitiu o pronto reconhecimento da independência do Suriname pelo governo Geisel (VIZENTINI, 2004:230). O primeiro contato oficial entre os dois países foi a visita do primeiroministro e chanceler surinamês Henck Arron, de 21 a 25 de julho de 1976. Nessa ocasião, foram assinados os primeiros tratados bilaterais e foi instituída uma comissão mista Brasil-Suriname para analisar os meios necessários a aumentar o intercâmbio comercial bilateral e a cooperação econômica, técnica e científica entre ambos (RPEB, 1976).

O Suriname também apareceu na política externa de Geisel em razão do Tratado de Cooperação Amazônica (TCA), assinado em 1978, juntamente com Bolívia, Peru, Equador, Colômbia, Venezuela e Guiana. Para o Brasil, era interessante aproximar-se dos vizinhos do Norte porque a maioria dos países amazônicos possuía reservas de petróleo e potencial para se tornar consumidor de produtos industrializados brasileiros. Alguns dos objetivos da diplomacia brasileira com o tratado eram: (i) trazer para as discussões a Guiana e o Suriname, tirandoos do isolamento a que estavam submetidos como ex-colônias (MIYAMOTO, 1989:149-150); (ii) afastar temores quanto ao suposto expansionismo brasileiro, a fim de criar uma base continental sólida para sua política externa independente (FERRIS, 1981:161); (iii) criar um clima cooperativo na bacia amazônica de modo a balancear as dificuldades sustentadas com a Argentina em torno do aproveitamento energético dos recursos hídricos da bacia do Prata (LAFER,1979:56; SPEKTOR, 2002:95).

A solução do contencioso em torno das usinas de Itaipu e de Corpus, pelo presidente Figueiredo em 1979, permitiu ao Brasil aprofundar a nova orientação sulamericana da política externa brasileira, timidamente iniciada no governo Geisel.

\section{O Brasil sob Figueiredo: um exercício de segurança sob a diretriz desenvolvimentista}

No ano da posse do presidente João Figueiredo, tiveram início transformações no cenário internacional que afetaram gravemente a posição do Brasil no mundo. Desde a primeira crise do petróleo de 1971, países subdesenvolvidos importadores líquidos de petróleo, como o Brasil, "tiveram de endividar-se para continuar a sustentar o nível de atividade”. Entretanto, antes de 1979, os petrodólares abundantes tinham mantido os juros internacionais a taxas praticamente negativas. Quando uma nova crise do petróleo assolou o planeta em 1979, o desequilíbrio nas balanças de pagamentos dos Estados Unidos e da América Latina provocou "a elevação descomunal das taxas de juros (agora flutuantes) dos empréstimos contraídos em dólar, com terríveis conseqüências para os tomadores". As taxas de 
juros atingiram picos de $21 \%$ ao ano a partir de 1979 , com efeitos avassaladores para a balança de pagamentos brasileira (ALMEIDA, 2001:116).

A eleição do republicano Ronald Reagan em 1980 para a presidência dos Estados Unidos levou à intensificação das hostilidades com a União Soviética. Para a América Latina, isso representou a retomada do enfoque ideológico dos conflitos e o abandono das tentativas de Diálogo Norte-Sul pelos Estados Unidos. As gestôes políticas norte-americanas na Nicarágua e em Granada demonstraram que os Estados Unidos não tinham pudores de utilizar meios militares para combater a ascensão de governos de esquerda no subcontinente.

Assim, a interrupção da détente e o acirramento do conflito ideológico LesteOeste promovidos pelo presidente dos Estados Unidos a partir de 1981, aliados à crise e ao desmantelamento do movimento terceiro-mundista, puseram fim às tentativas de diálogo Norte-Sul e às políticas reivindicatórias que se baseavam nessa divisão vertical do mundo (SENNES, 2003:66-73).

Nesse contexto que impelia a pensar as relações internacionais em termos de segurança, o desafio da diplomacia brasileira era prosseguir com a substituição da segurança pelo desenvolvimento como tema prioritário no âmbito interno, substituição essa iniciada com sucesso no governo do presidente Geisel. É certo que a política brasileira para o continente ainda mantinha uma atitude ideológica em relação ao desafio cubano. Para o governo, era indispensável lidar com os riscos de subversão interna, exportação de revoluções comunistas ou explosão de conflitos convencionais que pudessem trazer o conflito Leste-Oeste para o território da América do Sul. A novidade do governo de Figueiredo foi tentar fazê-lo de uma maneira que deixasse clara a opção brasileira por pensar as relações internacionais em termos de cooperação para o desenvolvimento.

É exatamente nessa encruzilhada que se situam as relações bilaterais entre Brasil e Suriname do período. Como visto, a alteração anormal da ordem política surinamesa que teve início com a "rebelião dos sargentos" em 1980 e se consolidou com o "massacre de dezembro" de 1982, trouxe consigo um potencial de radicalização à esquerda. Além disso, a reação da comunidade internacional aos eventos de 1982 - suspensão da ajuda financeira pelos Países Baixos e pelos Estados Unidos - forçou a liderança do Suriname a buscar outras fontes de recursos, ainda que fosse preciso flertar com países comunistas.

Após o golpe de 1980, o governo brasileiro mantivera sua posição tradicional de não-intervenção em assuntos internos de outros países (O GLOBO, 1980a). A rebelião dos sargentos apenas aumentou a atenção da diplomacia brasileira com relação ao país. No início de 1982, ainda sob a presidência de Henck Chin-A-Sen, o chanceler brasileiro Saraiva Guerreiro promoveu uma visita oficial ao Suriname. Em 25 de janeiro de 1982, Saraiva Guerreiro discursou em Paramaribo. O chanceler começou seu discurso descrevendo o contexto internacional e criticando a postura militarista dos Estados Unidos, ao estender automaticamente o conflito LesteOeste à América Latina: 
A cooperação internacional para o desenvolvimento é posta em plano secundário com relação a concepções centradas nos conceitos de segurança e poder. [...] Tensões provenientes de outras regiōes são transferidas a áreas do Terceiro Mundo, agravando freqüentemente a resolução de problemas regionais. Intensifica-se a corrida armamentista, [...] com um desperdício insano de recursos tão necessários à correção dos desequilíbrios econômicos internacionais (RPEB, 1982:61-62).

Está contida nesse discurso a "tese da cooperação necessária", segundo a qual a superação do subdesenvolvimento era a maneira mais eficaz de combater a subversão comunista (RIBAS, 2006). Assim, a promoção do desenvolvimento era essencial à segurança continental.

Saraiva Guerreiro prossegue seu discurso afirmando, implicitamente, que o Brasil pretendia adotar a tese da cooperação necessária nas suas relações com os países vizinhos:

Estamos permanentemente dispostos a renovar nossos esforços em favor do estabelecimento de uma ordem internacional caracterizada pelas relações de cooperação, e não de poder, pela igualdade, e não pela hegemonia [...]. (RPEB, 1982:62)

Critica implicitamente as condutas dos Estados Unidos e de Cuba com relação à América Central, os primeiros porque praticavam a intervenção nos assuntos internos e a última porque mantinha programas de exportação e fomento de movimentos revolucionários:

[...] o Brasil almeja que as situações de crise na região possam ser superadas, sem ingerências externas e com respeito à autodeterminação de seus povos, mediante o encaminhamento de soluções pacíficas e democráticas. (RPEB, 1982:62)

Assim, uma inovação da política externa brasileira sob o presidente Figueiredo, não apenas em relação ao Suriname, mas em relação a toda a América Latina, foi a utilização da tese da cooperação necessária para promover a substituição da identidade imperialista, subimperialista ou hegemônica que era atribuída ao Brasil, por outra cooperativa, confiável e igualitária nas relações com a região.

A identidade internacional de um país pode ser manejada por meio da política externa. A um país com uma política externa agressiva será atribuída uma identidade agressiva, assim como uma identidade cooperativa será atribuída a um país com uma política externa cooperativa. No cotidiano da vida internacional, ocorre uma constante reformulação das identidades internacionais de cada ator em face dos outros atores do sistema internacional.

Segundo Nicholas Onuf, é a linguagem que cria a identidade dos atores: a linguagem que utilizam torna-os o que eles são. "Policies exist only when we put 
our intentions into words and frame courses of action, or plans, to achieve them" (ONUF, 2001:77).

O caso da atuação brasileira no Suriname durante o governo Figueiredo demonstra a utilização conjunta das açōes e dos discursos. O que não estava dito no discurso diplomático brasileiro, mas pode ser lido em suas ações, era a defesa da eficácia da cooperação na contenção da subversão comunista. Aos países ricos, o Brasil afirmava que necessitava de mais cooperação para o desenvolvimento. À América do Sul, o Brasil sinalizava que seu comportamento passaria a ser pautado pela cooperação e pelo respeito incondicional à soberania dos países vizinhos.

Os fatos confirmam esse argumento, à medida que prossegue a narração do relacionamento bilateral Brasil-Suriname durante esse período.

A importância da visita de Saraiva Guerreiro ao Suriname não impediu que apenas dez dias depois, em 4 de fevereiro de 1982, Bouterse tomasse o poder no país e desse início a um processo de radicalização e aprofundamento do autoritarismo.

Com o massacre de dezembro de 1982, "tudo indicava que o Bouterse ia para uma posição de extrema esquerda, ligando-se a Cuba". Na opinião de Saraiva Guerreiro, os Países Baixos e os Estados Unidos suspenderam a ajuda ao Suriname porque acreditavam que "Bouterse não poderia durar muito sem a ajuda da Holanda”. O chanceler brasileiro, por sua vez, preferiu não estabelecer datas para a queda de Bouterse e, enquanto isso não ocorresse, era importante evitar o isolamento do Suriname. O governo brasileiro se manteve bem informado, inclusive com uma missão secreta do Serviço Nacional de Informaçôes (SNI) ao Suriname (GUERREIRO, 1985).

O temor brasileiro em relação à radicalização no Suriname, expresso em diversas ocasiōes na mídia escrita, se explicava porque Bouterse "começou a falar muito contra o imperialismo, contra os monopolistas, uma atitude de independência, Terceiro Mundo, países não alinhados, etc., em termos violentos”. Além disso, se mostrava "simpático à causa marxista, e via com agrado a possibilidade de explorar as relaçôes com o regime de Fidel Castro" (GUERREIRO, 1985). Segundo fontes do Ministério das Relações Exteriores, alguns fatos reveladores de uma tendência à esquerdização do Suriname eram:

a crescente influência de elementos de esquerda (Sittal, Mijnal e Joenmas) sobre o homem forte do regime, o Tenente-Coronel Desiré Bouterse; a designação de embaixadores da União Soviética e de Cuba ambos residentes em Paramaribo; o estabelecimento de relaçôes diplomáticas com a Coréia do Norte e o envio, em outubro último, de missão militar surinamesa a Pyongyang, capital deste último país. (CIEX, 1983c)

Os rumores de que Cuba e Líbia estavam enviando diplomatas e instrutores militares ao Suriname provocaram preocupações entre os governos brasileiro e norte-americano (MIYAMOTO, 1989:154; GUERREIRO, 1985). Porém, o 
Itamaraty não tinha elementos suficientes de convicção sobre a presença cubana no Suriname e sobre a sua conversão ao comunismo. O chanceler Saraiva Guerreiro entendia que "Bouterse não era um ideólogo marxista-leninista" (GUERREIRO, 1985). Portanto, o governo de Figueiredo acreditava que Bouterse poderia aceitar a inserção internacional de seu país no âmbito do Ocidente capitalista, desde que ela se mostrasse política e economicamente sustentável.

Desde 1980, o Brasil tinha poucas condiçôes de oferecer ajuda financeira ao Suriname ou a quem quer que fosse, em razão da crise da dívida. Naquele ano, o chanceler apresentou pessoalmente um projeto de cooperação com a Guiana e o Suriname ao presidente Figueiredo, "que achou ótimo, gostou muito das informações", mas replicou que não tinham dinheiro naquele momento para implementá-lo (GUERREIRO, 1985). Saraiva Guerreiro entendeu que era importante manter o Brasil como uma alternativa para Bouterse.

No começo de abril de 1983, teve início um rápido processo de inteligência que envolveu o presidente da República, membros do Conselho de Segurança Nacional, o chefe do Gabinete Militar, Danilo Venturini, o chefe do SNI, Octávio Aguiar de Medeiros, além do Ministro das Relaçōes Exteriores, Saraiva Guerreiro. O presidente decidiu "que o [ministro Danilo] Venturini fosse como emissário pessoal dele ao Suriname" (GUERREIRO, 1985) com o objetivo de contrapor-se à cubanização daquele país e "impedir que a América do Sul fosse envolvida pela confrontação Leste-Oeste” (MIYAMOTO, 1989:155). Venturini foi escolhido porque, além de ser membro do mais alto escalão do governo brasileiro, era militar, como Bouterse. Além disso, sendo militar, sua ida ao Suriname serviria como mensagem clara aos cubanos (CONDE, 1983).

Entre 15 e 17 abril de 1983, o general Venturini liderou uma missão diplomática ao Suriname, que foi composta também "pelo chefe da Divisão da América do Itamaraty, Osmar Vladimir Chohfi, [pelo] conselheiro Fagundes Fernando, [pelo] coronel Quijano, do Conselho de Segurança Nacional, e [pelo] coronel Carrocho, do Serviço Nacional de Informações (SNI)" (O ESTADO DE SÃO PAULO, 1983b). Programas de assistência civil e militar foram oferecidos a Paramaribo, incluindo cooperação técnica na área agro-industrial, estudos para a construção de usinas hidrelétricas e o aumento dos transportes aéreos e marítimos entre os países (CONDE, 1983), bem como "programas de treinamento militar, bolsas de estudo em universidades da Amazônia, substancial incremento do comércio bilateral e até transmissão via satélite de jogos de futebol brasileiros" (JORNAL DO BRASIL, 1983). Também foi oferecida uma linha de crédito no valor de US\$ 70 milhôes, utilizada principalmente para importar equipamentos militares de fabricação brasileira (MACDONALD, 1988:117).

Em entrevista à revista Veja, o general Octávio Medeiros afirmou que o processo decisório que culminou com a "missão Venturini" teve origem numa iniciativa da diplomacia norte-americana. Medeiros afirmou que os Estados 
Unidos estavam decididos a intervir no Suriname e chegaram a pedir a participação do Brasil com um batalhão de pára-quedistas. Vale transcrever um trecho da entrevista do general Medeiros:

Foi um choque, pois jamais pensamos em qualquer operação desse tipo. O Figueiredo começou a dar explicações: 'Olha, os senhores têm de entender que a situação do Brasil é difícil, temos uma opinião pública, não podemos sacrificar a imagem do governo, há essa grita toda contra a revolução...' [...] Sugeri que em vez de participar da invasão com um batalhão de pára-quedistas, fizéssemos um esforço com Bouterse, oferecendo ajuda técnica, econômica, material, em troca do afastamento dos cubanos. Voltamos aos americanos. O embaixador e o Clark conferenciaram e acharam que seria muito bom. Ficou acertado que suspenderiam a invasão e nós íamos fazer um esforço para entrar no Suriname com nossa influência. Deram um prazo: 'Se não conseguirem num prazo curto, aí uns dois ou três meses, vamos ter de entrar. Não podemos permitir o aumento da influência comunista no Caribe'. Então, montou-se a operação Venturini. (VEJA, 1997:54-55)

Na mesma reportagem, a revista Veja acrescentou um desmentido do general Venturini:

Procurado por VEJA, o general Venturini confirma os detalhes da operação em Paramaribo, mas faz uma ressalva importante: nega que, na reunião do Torto, os emissários dos EUA tenham feito um convite para o governo brasileiro participar da invasão do Suriname. "Se isso aconteceu, eu não soube", diz Venturini. (VEJA, 1997:55)

A disparidade entre os depoimentos de autoridades de mesmo nível hierárquico e igualmente imbricadas no processo decisório não permite concluir que tenha havido pressão norte-americana para intervir no Suriname, tampouco que essa tenha sido a origem da "missão Venturini". Com efeito, o Brasil pode ter agido mais por pressão americana do que por impulso próprio ou intençôes claras de sua parte, mas as fontes disponíveis não permitem dirimir essa dúvida.

À parte a polêmica sobre a iniciativa brasileira, a missão teve resultados. Ainda durante a visita, Bouterse disse a Venturini que "o Suriname está e pretende continuar na América do Sul, afastado como o Brasil de conflitos que lhe são estranhos". E reafirmou sua opção pela América do Sul: "O Suriname para os surinameses; o Brasil para os brasileiros; e a América do Sul para os sul-americanos" (O ESTADO DE SÃO PAULO, 1983b), clara referência à Doutrina Monroe e clara resposta ao intervencionismo norte-americano da época.

Para além dos discursos, houve resultados práticos: Bouterse decidiu reformular o programa de governo que seria anunciado no dia $1^{\circ}$ de maio, retirando-lhe o tom socializante (O ESTADO DE SÃO PAULO, 1983c); em junho de 1983, Bouterse demitiu o principal simpatizante de Cuba no governo 
surinamês, o então Ministro Badresein Sital (CONDE, 1983; JORNAL DE BRASÍLIA, 1983) e em 25 de outubro de 1983, o Suriname rebaixou a representação diplomática cubana em Paramaribo e suspendeu, com aquele país, todos os acordos anteriormente firmados (CIEX, 1983a; MIYAMOTO, 1989:157; JORNAL DO BRASIL, 1983b).

\section{Considerações finais}

O governo do presidente Figueiredo teve uma postura clara sobre a questão do Suriname: "resolveu bancar a estabilidade política do Suriname e aliviar as pressões dos EUA e dos Países Baixos sobre o país, que levariam o Coronel Bouterse aos braços de Fidel Castro" (JORNAL DO BRASIL, 1983b). Com isso, ajudou a afastar o Suriname de Cuba e, mais que isso, afastar a América do Sul do conflito Leste-Oeste. Segundo Rubens Ricupero, é "a ação brasileira que afasta o risco de uma intervenção americana [no Suriname], antes de Granada, e que abre o caminho para a futura redemocratização" (RICUPERO, 1996:51). Cervo e Bueno também destacam a atuação brasileira em 1983 como tendo sido decisiva "para evitar que a crise interna [no Suriname] tendesse a uma solução enquadrada pela presença cubana no conflito Leste-Oeste” (CERVO \& BUENO, 2002:451).

Mas a imprensa brasileira da época exagerou o papel do Brasil nesses acontecimentos, afirmando categoricamente que "o Brasil afastou a cubanização do Suriname" (O ESTADO DE SÃO PAULO, 1983b), como se esse efeito não tivesse dependido de outros aspectos da conjuntura internacional. É importante lembrar a atuação dos Estados Unidos, que não fez questão de esconder seus planos de apoiar um golpe de Estado para depor Bouterse e, em 25 de outubro de 1983, levou a cabo uma intervenção em Granada. Com efeito, no dia seguinte à intervenção americana, Bouterse foi à televisão dizer que pretendia "evitar os erros de Granada”, justificando com isso o rebaixamento da missão diplomática cubana e o pedido de retorno do embaixador Oscar Cardenas a Cuba (JORNAL DO BRASIL, 1983b).

Outro exagero é interpretar os atos do governo surinamês como uma resposta inequívoca rumo a uma aproximação com o Ocidente capitalista em detrimento do Leste comunista. O Suriname continuou mantendo intensas relações com a Líbia, com programas de assistência militar e financeira (JORNAL DO BRASIL, 1986; O ESTADO DE SÃO PAULO, 1986). Com a interrupção da barganha entre Brasil e Cuba, aproveitando-se do efeito simbólico do rebaixamento da delegação diplomática cubana, o Suriname pôde continuar praticando uma política externa pragmática - a exemplo da brasileira - sem amizades nem inimizades automáticas nem com os Estados Unidos nem com a União Soviética.

Ao mesmo tempo, as poucas análises acadêmicas existentes sobre o assunto minimizam os efeitos da atuação brasileira no Suriname, porque deixa de considerar sua importância discursiva na construção, durante os anos 1980, da 
nova identidade sul-americana do Brasil. A maneira exemplar como o Brasil se comportou deve ser entendida não apenas no âmbito restrito daquelas relaçôes bilaterais, mas deve ser considerada um ato de comunicação com os demais países sul-americanos, um ato de construção de confiança continental, afastamento das prevenções contra a possibilidade de um Brasil hegemonista e subimperialista.

O momento histórico descrito no presente artigo indica importantes regularidades no comportamento de Brasil e Suriname. A conduta brasileira mostra como o País respondeu aos desafios de segurança típicos dos anos 1980, combinando tradições diplomáticas que vão do juridicismo ao pragmatismo, com o objetivo de construir uma imagem confiável perante a América do Sul. Com medidas como a "missão Venturini" enviada ao Suriname, o Brasil logrou formar uma rede de paz e cooperação no subcontinente, que foi determinante para o aprofundamento da integração regional nos anos 1990 sob a égide do Mercosul.

A conduta surinamesa mostra que sua liderança golpista também soube agir com pragmatismo. Utilizou-se de atos de efeito retórico grandioso, como o afastamento em relação a Cuba, para buscar uma acomodação com os EUA, via Brasil, evitando assim sua queda e criando espaço de manobra para seu projeto de poder.

\section{Referências bibliográficas}

\section{Fontes documentais}

CIEX (Centro de Informações do Exterior), Ministério das Relações Exteriores, Brasil. (1983a) Informe secreto CIEX no. 160/83, de 19/12/1983.

CIEX (Centro de Informaçōes do Exterior), Ministério das Relações Exteriores, Brasil. (1983b) Informe secreto CIEX no. 014/83, de 24/2/1983.

CIEX (Centro de Informações do Exterior), Ministério das Relações Exteriores, Brasil. (1983c) RPB secreto CIEX no. 013/83, de 10/2/1983.

GUERREIRO, Ramiro Saraiva. (1985) Depoimento, Rio de Janeiro: Centro de Pesquisa e Documentação de História Contemporânea do Brasil (CPDOC), Fundação Getúlio Vargas (FGV). Entrevista concedida entre 19/3/1985 e 11/4/1985, versão digitada, fita 28.

RESENHA DE POLÍTICA EXTERIOR DO BRASIL. (1982) “Os entendimentos do chanceler brasileiro com o Suriname e com a Guiana”, RPEB no. 32, p. 61-77.

RESENHA DE POLÍTICA EXTERIOR DO BRASIL. (1976) "Brasil recebe o primeiroministro e chanceler do Suriname”, RPEB, ano III, no. IX, p. 39-44.

\section{Livros e periódicos}

ALMEIDA, Paulo Roberto de. (2001) "As duas últimas décadas do século XX: fim do socialismo e retomada da globalização”, in J. F. S. Saraiva (org.), Relaçôes internacionais: dois séculos de história: entre a ordem bipolar e o policentrismo (de 1947 a nossos dias). Brasília: IBRI, p. 91-174. 
ATKINS, G. Pope. (1999) Latin America and the Caribbean in the International System, Boulder-CO: Westview Press.

CERVO, Amado L. e BUENO, Clodoaldo. (2002) História da politica exterior do Brasil. Brasília, EdUnb.

COPINSCHI, Philippe. (2007) “Governance in African Oil-Producing Countries: State, Multinational Companies and Civil Society Organizations”, Cena Internacional 9 (1), p. 123-139.

DEW, Edward. (1983) "Suriname Tar Baby: The Signature of Terror", Caribbean Review 12 (1), p. 4-7, 34.

FERRIS, Elizabeth G. (1981) “The Andean Pact and the Amazon Treaty: Reflections of Changing Latin American Relations", Journal of Interamerican Studies and World Affairs 23 (2), p. 147-175.

GADDIS, John Lewis. (1997) We Now Know: Rethinking Cold War History, Oxford: Oxford University Press.

KELLY, Philip L. (1984) "Geopolitical Themes in the Writings of General Carlos de Meira Mattos of Brazil”, Journal of Latin American Studies 16 (2), p. 439-461.

KRUEGER, Anne O. (1990) "Government Failures in Development", Journal of Economic Perspectives 4 (3), p. 9-23.

LAFER, Celso. (1979) "Política exterior brasileira: balanço e perspectivas”, Dados 22, p. 49-62.

MACDONALD, Scott B. (1988) "Insurrection and Redemocratization in Suriname?: The Ascendancy of the 'Third Path", Journal of Interamerican Studies and World Affairs 30 (1), p. 105-132.

MIYAMOTO, Shiguenoli. (1989) "Diplomacia e militarismo: o Projeto Calha Norte e a ocupação do espaço amazônico", Revista Brasileira de Ciência Política 1 (1), p. 145-163.

MONIZ BANDEIRA, Luiz Alberto. (2003) Brasil, Argentina e Estados Unidos: conflito e integração na América do Sul (da Tríplice Aliança ao Mercosul - 1870-2003), Rio de Janeiro: Revan.

ONUF, Nicholas. (2001) "Speaking of Policy", in V. Kubálková (ed.), Foreign Policy in a Constructed World, London, New York: M.E.Sharpe.

PINHEIRO, Leticia de Abreu. (2004) Politica externa brasileira. Rio de Janeiro: Jorge Zahar Editor.

PINHEIRO, Leticia de Abreu. (1987) Foreign policy decision-making under the Geisel government: the President, the military and the foreign ministry. Tese (PhD em Relações Internacionais) - London School of Economics and Political Sciences, Londres.

RIBAS, Marcelo de Oliveira. (2006) “A 'cooperação necessária' como idéia-força na política exterior do Brasil (1958-2005)”, Dissertação (Mestrado em Relações Internacionais) Universidade de Brasília, Brasília.

RICUPERO, Rubens. (1996) "Brasil, América Latina e os EUA desde 1930: 60 anos de uma relação triangular”, in José Augusto Guilhon Albuquerque (org.), Sessenta anos de política externa brasileira (1930-1990): Crescimento, modernização e política externa (v. 1). São Paulo: Cultura Editores Associados, p. 37-60.

SENNES, Ricardo. (2003) As mudanças da política externa brasileira nos anos 1980: uma potência média recém-industrializada, Porto Alegre: Editora da UFRGS. 
SPEKTOR, Matias. (2002) "Ruptura e legado: o colapso da cordialidade oficial e a construção da parceria entre o Brasil e a Argentina (1967-1979)", Dissertação (Mestrado em Relações Internacionais), Universidade de Brasília: Brasília.

URT, João Nackle. (2009) "Construção de confiança na América do Sul: a política externa do governo Figueiredo (1979-1985)”, dissertação (Mestrado em Relaçôes Internacionais), Universidade de Brasília: Brasília.

VIZENTINI, Paulo G. Fagundes. (2004) Politica externa do regime militar brasileiro: multilateralização, desenvolvimento e construção de uma potência média (1964-1985). Porto Alegre: Ed. UFRGS.

\section{Jornais e revistas cotidianos}

CARLOS, Newton. (1980) “Geopolítica para os sargentos do Suriname”, Correio Braziliense, Brasília, 28/2/1980.

CONDE, Carlos. (1983) "Brazil in Suriname: See How a Regional Power Acts", World Paper, p. 14.

CORREIO BRAZILIENSE. (1982) "Golpe militar tem êxito em Suriname", Brasília, 12/3/1982.

ESTADO DE SÃO PAULO, O. (1982) "Diplomatas confirmam ação de cubanos no Suriname", São Paulo, 22/12/1982.

ESTADO DE SÃO PAULO, O. (1983a) “Bouterse matou dois de seus opositores”, São Paulo, 5/6/1983.

ESTADO DE SÃO PAULO, O. (1983b) “Missão no Suriname afastou 'cubanização”, São Paulo, 20/4/1983.

ESTADO DE SÃO PAULO, O. (1983c) “Embaixador cubano sai do Suriname”, São Paulo, 27/10/1983.

ESTADO DE SÃO PAULO, O. (1986) “Suriname tem ajuda militar da Líbia”, São Paulo, $17 / 12 / 1986$.

FOLHA DE S. PAULO. (1982a) "Forças Armadas do Surinã dão golpe e assumem poder", São Paulo, 6/2/1982.

FOLHA DE S. PAULO. (1982b) "No Surinã, um sargento lidera golpe de Estado", São Paulo, 12/3/1982.

FOLHA DE S. PAULO. (1982c) “No Surinã, Exército assume plenos poderes”, São Paulo, 9/12/1982.

GLOBO, O. (1980a) "Rebelião de sargentos derruba Governo do Suriname", Rio de Janeiro, 26/2/1980.

GLOBO, O. (1980b) “Sargentos prometem entregar o poder aos civis no Suriname”, Rio de Janeiro, 27/2/1980.

GLOBO, O. (1980c) "Sindicalista pode integrar o novo governo do Suriname", Rio de Janeiro, 3/3/1980.

GLOBO, O. (1982a) “Militares do Suriname afastam premier civil”, Rio de Janeiro, 6/2/1982.

GLOBO, O. (1982b) "Esquerda foi deposta no Suriname, dizem rebeldes", Rio de Janeiro, 12/3/1982. 
GLOBO, O. (1982c) "Repressão no Suriname: Cuba e Nicarágua acusadas", Rio de Janeiro, $14 / 12 / 1982$.

JORNAL DA TARDE. (1982) “O fim do golpe no Suriname”, 15/3/1982.

JORNAL DE BRASÍLIA. (1980) “Golpe militar no Suriname”, Brasília, 26/2/1980.

JORNAL DE BRASÍLIA. (1983) “Suriname cumpre sua parte no jogo”, Brasília, 15/6/1983.

JORNAL DO BRASIL. (1980a) "Sargentos dão golpe e tomam poder em Suriname”, Rio de Janeiro, 26/2/1980.

JORNAL DO BRASIL. (1980b) “Suriname sob censura é controlado por sargentos", Rio de Janeiro, 27/2/1980.

JORNAL DO BRASIL. (1980c) "Suriname suspende eleições e não diz quando serão feitas", Rio de Janeiro, 29/2/1980.

JORNAL DO BRASIL. (1982a) "Militares tiram Presidente e controlam o Suriname", Rio de Janeiro, 6/2/1982.

JORNAL DO BRASIL. (1982b) "Esquerdização e repressão no Suriname preocupam EUA", Rio de Janeiro, 26/12/1982.

JORNAL DO BRASIL. (1983a) “Mistérios demais”, Rio de Janeiro, editoral do dia 22/4/1983.

JORNAL DO BRASIL. (1983b) “Suriname dá 14 dias para Cuba retirar diplomatas”, Rio de Janeiro, 27/10/1983.

JORNAL DO BRASIL. "Suriname assinou acordo militar com governo líbio", Rio de Janeiro, $17 / 12 / 1986$.

VEJA. (1997) "Memórias do SNI: O general Medeiros faz revelaçōes sobre o governo Figueiredo, a Guerra das Malvinas e o Suriname”, edição 1503, ano 3 (27), 9/7/1997, p. 54-59.

Recebido em 25 de maio de 2009 Aprovado em 27 de setembro de 2009

\section{Resumo}

Entre 1975 e 1985, observa-se a atuação do Brasil para assegurar relações confiáveis com o Suriname, bem como as primeiras manifestações da identidade internacional surinamesa. Destaca-se a missão diplomática brasileira enviada ao Suriname após o golpe de Estado de 1982, o qual indicava a possível "cubanização" desse país.

\section{Abstract}

Between 1975 and 1985, Brazil's efforts to warrant reliable relations with Suriname, as well as Suriname's first international identity manifestations can be observed. The analysis focuses the Brazilian diplomatic mission dispatched to Suriname after the 1982 coup d'État, which indicated a possible 'cubanization' of this country.

Palavras-chave: Suriname - Brasil - relações bilaterais

Keywords: Suriname - Brazil - bilateral relations 